\title{
Multicystic Lesion in Jaws: A Rare Case Report on Gorlin-Goltz Syndrome
}

\author{
Pradeep Acharya*1, Ashok Dongol1', Anjani K. Yadav1, Vivek k. Mahato², \\ Rishikesh Pratap Sah ${ }^{3}$, Mehul R. Jaisani4 ${ }^{4}$
}

B. P. Koirala Institute of Health Sciences, Dharan, Nepal

${ }^{1}$ Assistant Professor, Dept. of Oral and Maxillofacial Surgery, BPKIHS, Dharan, Nepal
2Junior Resident, Dept. of Oral and Maxillofacial Surgery, BPKIHS, Dharan, Nepal
${ }^{3}$ Assistant Professor, Dept. of Dental Surgery, JMC-Teaching Hospital, Ramdaiya, Janakpur, Nepal
${ }^{4}$ Associate Professor, Dept. of Oral and Maxillofacial Surgery, BPKIHS, Dharan, Nepal

\begin{abstract}
Background and Objectives: Gorlin-Goltz syndrome is an uncommon autosomal dominant inherited disorder, which is characterized by multiple odontogenickeratocysts (OKC) and basal cell carcinomas, skeletal, dental, ophthalmic and neurological abnormalities.

Material and Methods: Thirteen years old male patient came with swelling of left maxilla obliterating buccal vestibule with pus discharge for 1 month. The orthopantomograph and computed tomography scan demonstrated multiple lytic lesions in maxilla and mandible. Incisional biopsy was suggestive of odontogenickeratocyst (OKC). Besides multiple OKCs; bifid ribs, palmer pits and hypertelorism were present supporting for the diagnosis as Gorlin-Goltz Syndrome.
\end{abstract}

Results: The classical treatment of KCOT with enucleation with curettage or resection would have resulted in significant morbidity. Therefore we first decompressed and then enucleated the cysts.

Conclusion: Gorlin-Goltz syndrome is a rare entity and the multiple KCOT can be managed with decompression followed by enucleation.

Keywords: Odontogenickeratocyst, Gorlin-Goltz Syndrome, Decompression, Enucleation

\section{INTRODUCTION}

Gorlin-Goltz syndrome, which is also known as nevoid basal cell carcinoma (BCC) Syndrome is a rare autosomal dominant disorder with strong penetrance and extremely variable expressivity. It was reported by Jarish and White in 1894. Robert
J. Gorlin and Robort W. Goltz described the distinct syndrome, consisting of multiple nevoid BCCs, jaw cysts, and bifid ribs. It is characterized by multiple odontogenickeratocysts (OKC), multiple BCCs, skeletal, dental, ophthalmic, and neurological abnormalities, intracranial 
ectopic calcifications of the falxcerebri and facial dysmorphism[1,2]. Pathogenesis of the syndrome is attributed to abnormalities in the long arm of chromosome 9 (q22.3-q31) and loss of or mutations of human patched gene (PTCH1 gene). Diagnosis isbased upon established major and minor clinical and radiological criteria and ideally confirmed by deoxyribonucleic acid (DNA) analysis.The frequency of the syndrome varies according to the country where the study has been carried out. On an average, the incidence of Gorlin-Goltz syndrome has been reported to be 1 in 50,000 to 150,000 in general population [3].

The syndrome manifests with some major and minor criteria like pigmented BCCs, OKC, palmar and/or plantarpits, and ectopic calcifications of the falxcerebri. To establish diagnosis, two major and one minor or one major and three minor criteria are necessary. Treatment modalities may differ for small and large cysts. Small cysts can be enucleated, whereas large cysts can be marsupialized. Because of aggressive nature and high rate of recurrence, there should be periodic followup at regular intervals of 6 months till 5 years, followed by once annually for the entire life.

\section{CASE DESCRIPTION}

A 13 years -old male patient came to the Department of Oral and Maxillofacial Surgery, with chief complaint of swelling in left upper jaw (figure1) for 1 month and the case was studied from April to July 2017 at BPKIHS, Dharan, Nepal. Swelling was increasing, not associated with pain. Intraoral examination revealed obliteration of buccal vestibule from region of 22 to 26 with pus discharge, having no missing tooth specific to his age

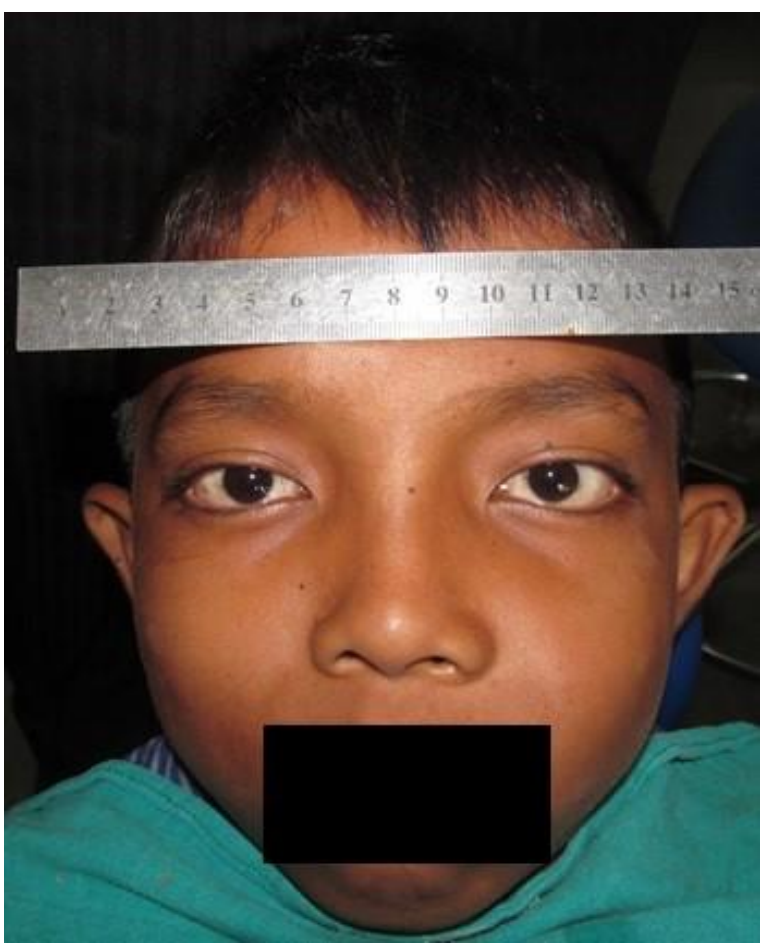

Figure 1: Clinical photograph showing left maxillary swelling and hypertelorism. (Eyes are not blinded to show hypertelorism)

Orthopantomogram (OPG) was advised which revealed lytic swelling in left maxillary area causing the cortical bone erosion along with additional lytic areas in right posterior maxilla and left posterior mandible. Thus, three cystic lesions (two in maxilla and one in mandible) were seen on OPG (figure 2).

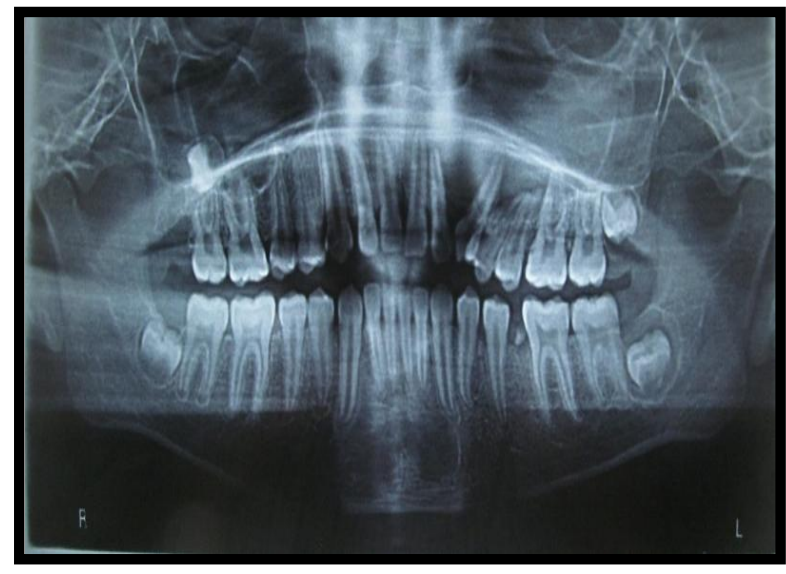

Figure 2: Orthopantomogram showing radiolucencies in left maxillary area; right maxillary and left mandibular third molar area 
Due to the presence of multiple cyst-like lesions in the jaws, Gorlin-Goltz syndrome was suspected and further investigations were carried out. CT scan of maxilla and mandible also suggested similar lytic swellings.

Chest X-ray showed bifid right $4^{\text {th }}$ rib posteriorly. Other findings included palmar pits, hypertelorism. No evidence of basal cell carcinoma or calcification of falxcerebri on skull X-ray was found.Aspiration from the swelling yielded blood mixed fluid.

Decompression along with incisional biopsy was planned simultaneously. Decompression was achieved using a cut end of Foley's catheter of approx. $4 \mathrm{~cm}$ length kept in the biopsy site of left maxilla for 3 months. Incisional biopsy was suggestive of keratocysticodontogenic tumor.

Swelling was reduced significantly after 3 months and bone formation was evident on CT scan (figure 3). After that surgical enucleation was done for all three lesions under GA.

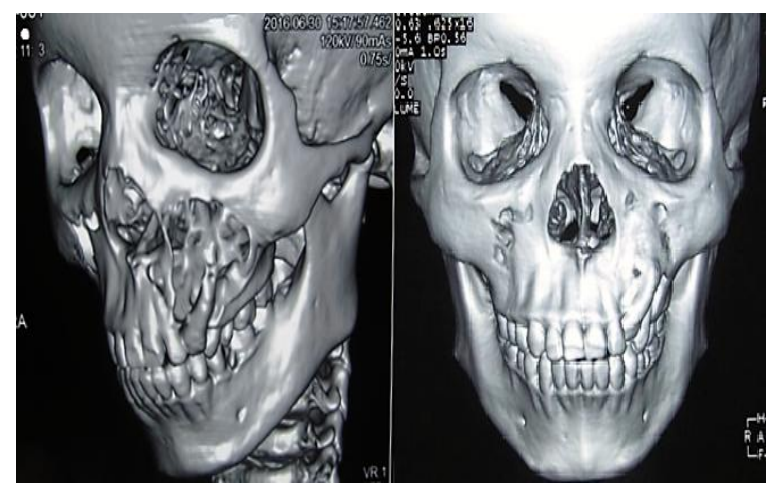

Figure 3: Pre- and Post- decompression 3D CT scan of left maxilla

\section{DISCUSSION}

Evans et al. first established major and minor criteria for the diagnosis of the syndrome and later were modified by Kimoni set al. in 2004
$[1,2]$. The presence of two major and one minor or one major and three minor criteria are necessary to establish diagnosis.

\section{Gorlin-Goltz Syndrome}

\section{Major criteria}

- Multiple basal cell carcinomas or one occurring under the age of 20 years.

- Histologically proven OKCs of the jaws.

- Palmar or plantar pits (three or more).

- Bilamellar calcifications of the falxcerebri.

- Bifid, fused, or markedly splayed ribs.

- First degree relative with nevoid basal cell carcinoma syndrome.

\section{Minor criteria}

- Macrocephaly (adjusted for height).

- Congenital malformation: Cleft lip or cleft palate, frontal bossing, coarse face moderate or severe hypertelorism.

- Other skeletal abnormalities: Sprengel deformity, marked pectus deformity, marked syndactyly of the digits.

- Radiological abnormalities: Bulging of sellaturcica, vertebral anomalies such as hemi vertebrae, fusion or elongation of vertebral bodies, modeling defects of the hands and feet, or flame-shaped hands or feet.

- Ovarianfibroma.

- Medulloblastoma.

In this patient, the diagnosis of Gorlin-Goltz syndrome was established by the presence of three major criteria (multiple OKC, bifid ribs, and palmer pits) and one minor criterion (hypertelorism).

Gorlin-Goltz syndrome is an autosomal dominant disorder with a high penetrance 
and variable expressivity. Not many cases have been reported in Nepal, and hence we report here a rarecase and importance of multidisciplinary approach in management of the syndrome. Thorough extra oral and intraoral examinations along with OPG, skull and chest radiographs help in proper diagnosis of the condition. This investigation prompts an early verification of the disease, which is very important to prevent recurrence and better survival rates Drosophila gene mapped to chromosome 9q21-23.

Woolgaret al. [4] in 1987 concluded that mean age group for syndromic cases is 10 to 30 years and females are more affected than males. In syndromic cases, more commonly maxillary molar area is affected.Recurrence rate is higher in syndromic cases $(63 \%)$.

Giuliani et al. [5] in 2006 concluded large multilocularkeratocysts might be treated with a conservative approach, the only disadvantages being the extended therapeutic time and the frequent and recurrent medications.

Pogrel (2005) [6] concluded that, decompression and/or marsupialization has at least as high a success rate as the other more aggressive treatments with lower morbidity and preservation of important vital structures. Decompression was done in this case at the time of incisional biopsy from the large lesion, which was present on upper left posterior jaw followed by enucleation of all three cyst.

\section{CONCLUSION}

Gorlin-Goltz syndrome is a well-known Autosomal Dominant disorder. The incidence reported worldwide ranges from 1 in 50,000 to 1 in 1,50000. OKC of the jaws, which can cause disfigurement of the face, mobility andeven loss of teeth can be avoided by early detection and treatment of the same. For large cysts with significant morbidity, decompression followed by marsupialization can be done.

\section{ACKNOWLEDGEMENT}

Authors would like to acknowledge the patient who permitted to get it published. And we are thankful to the whole team of Department of Oral and Maxillofacial surgery of BPKIHS for the valuable suggestions and co-operation.

\section{AUTHOR'S CONTRIBUTION}

PA- principle author of the article; AD, AKY, VKM,RPS- involved with the patient management and editing of the article, MRJsupervision and review of the article.

ETHICAL CONSIDERATION: Ethical approval letter was obtained from BPKIHS, Dharan and written informed consent was taken from patients prior to study.

SOURCE OF SUPPORT: Department of Oral and Maxillofacial Surgery, BP Koirala Institute of Health Sciences, Dharan, Nepal.

CONFLICT OF INTEREST: There's no conflict of interest regarding the publication of this paper. It has not been presented till date in any forms.

\section{REFERENCES}

1. Evans D, Ladusans E, Rimmer S, Burnell L, Thakker N, Farndon P. Complications of the naevoid basal cell carcinoma syndrome: results of a population based study. J Med Genet [Internet]. 1993;30(2):460-4

2. Kimonis VE, Mehta SG, Digiovanna JJ, Bale SJ PB. Radiological features in 82 patients with nevoid basal cell carcinoma (NBCC or Gorlin) syndrome. 
Genet Med. 2004;6(6):495-502

3.Joshi PS, Deshmukh V GS. Gorlin-goltz syndrome. Dent Res J (Isfahan). 9(1):100

4. Woolgar JA, Rippin JW BR. The odontogenic keratocyst and its occurrence in the nevoid basal cell carcinoma syndrome. Oral surgery, oral Med oral Pathol. 1987;64(6):727-30

5. Giuliani M, Grossi GB, Lajolo C, Bisceglia M, Herb KE. Conservative management of a large odontogenic keratocyst: Report of a case and review of the literature. J Oral Maxillofac Surg. 2006;64(2):308-16

6. Pogrel MA. Treatment of keratocysts: The case for decompression and marsupialization. J Oral Maxillofac Surg. 2005;63(11):1667-73

Correspondence to:

Dear Dr. Pradeep Acharya

Assistant Professor

Department of Oral and Maxillofacial Surgery

BPKIHS, Dharan, Nepal

Email: pradeepddh@gmail.com 